\title{
A SHORT PROOF OF AN INEQUALITY OF CARLESON'S
}

\author{
CHARLES W. NEVILLE ${ }^{1}$
}

\begin{abstract}
We give a simple proof that if $a_{i}, i=1,2, \ldots$, is a uniformly separated sequence in the unit disk, then $\Sigma\left(1-\left|a_{i}\right|^{2}\right)\left|f\left(a_{i}\right)\right|^{p}<K\|f\|_{p}^{p}$, for all $f \in H^{p}$ and $1<p<\infty$.
\end{abstract}

Let $\mathbf{C}$ denote the complex plane, $\Delta(a, r)$ denote the disk $\{z:|z-a|<r\}$, and let $H^{p}$ denote Hardy class $H^{p}$ of $\Delta(0,1)$ for $1 \leqslant p \leqslant \infty$. The key step in the duality proof of the Carleson interpolation theorem is to prove

LemMA 1. Let $a_{i}, i=1,2, \ldots$, be a uniformly separated sequence in $\Delta(0,1)$. Then

$$
\sum\left(1-\left|a_{i}\right|^{2}\right)\left|f\left(a_{i}\right)\right|^{p} \leqslant K\|f\|_{p}^{p}
$$

for all $f \in H^{p}$ and $1 \leqslant \dot{p}<\infty$.

If $\left|B_{i}\left(a_{i}\right)\right| \geqslant \delta$ for all $i$, where $B_{i}$ is the Blaschke product vanishing on $\left\{a_{j}\right.$ : $j \neq i$, then the best value of $K$ is $C \ln (1 / \delta)$, which comes from Carleson's proof [1] tempered with maximal functions. (I want to thank the referee for pointing this out to me.) We shall give a much simpler proof that $K<\infty$, although our value for $K$ will not be as good. We shall show that if $0<\delta \leqslant \frac{1}{2}$, then we may choose

$$
K=32 / \delta^{4}
$$

We shall need the Hilbert space $A^{2,1}=\{f$ analytic on $\Delta(0,1)$ : $\left.\pi^{-1} \int_{\Delta(0,1)}|f(z)|^{2}\left(1-|z|^{2}\right) d x d y<\infty\right\}$. The $A^{2,1}$ norm of $f(z)=\Sigma c_{n} z^{n}$ is easily seen to be $\Sigma\left|c_{n}\right|^{2} /(n+1)(n+2)$. Clearly $A^{2,1}=\left\{f^{\prime}: f \in H^{2}\right\}$ and $\left\|f^{\prime}\right\|_{2,1} \leqslant\|f\|_{2}$. The following lemma, concerning sums of squares of normalized point evaluations in $A^{2,1}$, was given in slightly different form by Shapiro and Shields [4, p. 529].

Lemma 2. Let $b_{i}, i=1,2, \ldots$, be a sequence in $\Delta(0,1)$. Suppose $0<\eta \leqslant \frac{1}{2}$ and $\left|b_{i}-b_{j}\right| /\left|1-b_{i} \bar{b}_{j}\right| \geqslant \eta$ if $i \neq j$. Then

$$
\sum\left(1-\left|b_{i}\right|^{2}\right)^{3}\left|f\left(b_{i}\right)\right|^{2} \leqslant 32 \eta^{-2}\|f\|_{2,1}^{2}
$$

for all $f \in A^{2,1}$.

Received by the editors June 11, 1976 and, in revised form, November 24, 1976.

AMS (MOS) subject classifications (1970). Primary 30A04, 30A80, 30A78.

Key words and phrases. Carleson interpolation theorem, $H^{p}$ space, Blaschke product, $A^{2,1}$ space, uniformly separated sequence.

${ }^{1}$ I would like to thank L. A. Rubel for interesting me in interpolation problems, and Carleton University for making it possible for me to attend a series of lectures he gave there. 
Proof. A little computation using the conformal invariance of the pseudohyperbolic metric $\rho\left(b_{i}, b_{j}\right)=\left|b_{i}-b_{j}\right| /\left|1-b_{i} \bar{b}_{j}\right|$ shows that

$$
\Delta\left(b_{i},\left(\frac{1}{2}\right) \eta\left(1-\left|b_{i}\right|^{2}\right)\right) \subseteq\left\{z: \rho\left(b_{i}, z_{j}\right)<\eta\right\} .
$$

Thus the disks $\Delta\left(b_{i},\left(\frac{1}{4}\right) \eta\left(1-\left|b_{i}\right|^{2}\right)\right)=\Delta\left(b_{i}, s_{i}\right), i=1,2, \ldots$, are disjoint. Hence

$$
\begin{aligned}
\left(1-b_{i}^{2}\right)^{3}\left|f\left(b_{i}\right)\right|^{2} & \leqslant 16 \pi^{-1} \eta^{-2} \int_{\Delta\left(b_{i}, s_{i}\right)}\left(1-\left|b_{i}\right|^{2}\right)|f(z)|^{2} d x d y \\
& \leqslant 32 \pi^{-1} \eta^{-2} \int_{\Delta\left(b_{i}, s_{i}\right)}\left(1-|z|^{2}\right)|f(z)|^{2} d x d y .
\end{aligned}
$$

By summing (2) over all $i$, we obtain Lemma 2 .

ProOF OF Lemma 1. It clearly suffices to prove Lemma 1 for $p=2$ (cf. [2, p. 152]). Let $B$ be the Blaschke product vanishing at $\left\{a_{i}: i=1,2, \ldots\right\}$. Let $f \in H^{2}$. Then $\left\|(B f)^{\prime}\right\|_{2,1} \leqslant\|B f\|_{2}=\|f\|_{2}$. But

$$
\left|(B f)^{\prime}\left(a_{i}\right)\right|=\left|B^{\prime}\left(a_{i}\right) f\left(a_{i}\right)\right|=\left(1-\left|a_{i}\right|^{2}\right)^{-1}\left|B_{i}\left(a_{i}\right) f\left(a_{i}\right)\right| .
$$

Thus

$$
\begin{aligned}
\sum\left(1-\left|a_{i}\right|^{2}\right)\left|f\left(a_{i}\right)\right|^{2} & =\sum\left|B_{i}\left(a_{i}\right)\right|^{-2}\left(1-\left|a_{i}\right|^{2}\right)^{3}\left|(B f)^{\prime}\left(a_{i}\right)\right|^{2} \\
& \leqslant 32 \delta^{-4}\left\|(B f)^{\prime}\right\|_{2,1}^{2} \leqslant 32 \delta^{-4}\|f\|_{2}^{2} .
\end{aligned}
$$

This completes the proof of Lemma 1 and of equality (1).

\section{REFERENCES}

1. L. Carleson, An interpolation problem for bounded analytic functions, Amer. J. Math. 80(1958), 921-930. MR 22 \#8129.

2. P. L. Duren, Theory of $H^{p}$ spaces, Academic Press, New York, 1970. MR 42 \#3552.

3. J. P. Earl, On the interpolation of bounded sequences by bounded functions, J. London Math. Soc. (2) 2(1970), 544-548 MR 44 \# 1813.

4. H. S. Shapiro and A. L. Shields, On some interpolation problems for analytic functions, Amer. J. Math. 83(1961), 513-532. MR 24 \# A3280.

Department of Mathematics, Central Connecticut State College, New Britain, CONNECTICUT 06050 